\title{
A OBJEÇÃO DE THOMAS REID À TEORIA LOCKIANA DA IDENTIDADE PESSOAL
}

Thomas ReID's ObJection to Locke's Theory of PERSONAL IDENTITY

\author{
VINÍCIUS FRANÇA FREITAS \\ UFMG (pós-doutorando / PNPD-CAPES), BRASIL \\ ffvinicius@yahoo.com.br
}

\begin{abstract}
The paper aims to present two distinct ways of defending John Locke's theory of personal identity from Thomas Reid's objection. First, it will be argued that this objection is not effective since it starts from a misunderstanding of Locke's theory. The identity of a person is not preserved by the psychological continuity of consciousness, as Reid understood it, but by its ontological continuity: the existence of the same consciousness preserves the personal identity. Secondly, it will be argued that it is possible to reply to that objection in the light of the observation that the personal identity is preserved by the identity of the man: person and man are connected by means of the notion of body.
\end{abstract}

Key Words: John Locke • Thomas Reid • consciousness • personal identity • self

\section{Introdução}

John Locke (1632-1704) apresenta sua teoria da identidade pessoal no capítulo 'Da identidade e diversidade' da segunda edição do Ensaio sobre o entendimento humano ${ }^{1}$ (1694). Nos anos que se seguiram à publicação da obra, o debate sobre a questão se tornou popular entre os autores britânicos ${ }^{2}$ e a compreensão lockiana do que constitui a mesma pessoa tornou-se alvo de críticas ${ }^{3}$. Dentre estas críticas, a objeção realizada por Thomas Reid (1710-1796), nos Ensaios sobre os poderes intelectuais do homem (1785), tornou-se uma das mais discutidas na literatura secundária. Se, tal como Locke supõe, a consciência produz a identidade pessoal, como ele poderia explicar que uma pessoa do passado é a mesma pessoa do presente se esta última não tem consciência de alguns dos pensamentos e ações daquela primeira? Reid resume sua objeção por meio do exemplo do oficial corajoso:

Suponhamos que um corajoso oficial, que fora açoitado quando garoto na escola por roubar um pomar, tenha tomado o estandarte do inimigo em sua primeira campanha e, mais tarde, em sua vida, tenha se tornado um general. Suponhamos também, o que se deve admitir como possível, que quando ele 
tomou o estandarte, ele estava consciente de ter sido açoitado na escola e que, quando se tornou um general, ele estava consciente de ter tomado o estandarte, mas perdera completamente a consciência de seu açoitamento (Reid, 2002, p.276, tradução minha).

Tal como Reid a entende, a consequência da teoria lockiana é que "[...] um homem pode ser e, ao mesmo tempo pode não ser, a pessoa que realizou uma ação particular" (2002, p.276, tradução minha).

O objetivo do artigo é defender a teoria lockiana da identidade pessoal da objeção de Reid. A minha hipótese sugere que esta tarefa pode ser realizada de duas maneiras. Em primeiro lugar, notando que a objeção se baseia em uma interpretação equivocada da teoria lockiana. Diferentemente do que pensa Reid, a teoria de Locke não é baseada sobre a continuidade psicológica da consciência, mas sim sobre a continuidade ontológica desta faculdade. A pessoa é a mesma pessoa desde que uma mesma consciência continue a existir ao longo do tempo. Neste sentido, há um pressuposto ontológico na teoria lockiana que preserva a identidade da pessoa para além das operações da faculdade da consciência. Em segundo lugar, é possível defendê-la respondendo a objeção nos termos colocados por Reid, isto é, considerando a incapacidade da consciência de atestar todos os fatos do passado. Nestes casos, noto que que a identidade do homem é capaz de preservar a identidade da pessoa. Locke distingue as noções de homem e pessoa. Contudo, ambas estão conectadas pelo corpo. Para Locke, a identidade pessoal envolve não apenas um aspecto mental como um aspecto corporal. Esta dimensão corporal do eu permite que a pessoa esteja ligada ao homem, de modo que a pessoa é a mesma ao longo do tempo desde que ela seja o mesmo homem, embora possa não estar consciente de todos os episódios passados de sua vida.

Nas seções seguintes, (2) apresento minha interpretação da teoria lockiana da identidade pessoal; (3) discuto minha primeira tentativa defender a teoria lockiana da objeção de Reid, argumentando que esta teoria é fundada sobre a continuidade ontológica da consciência e não sobre sua continuidade psicológica; e, por fim, (4) discuto minha segunda tentativa de defender a teoria de Locke, sublinhando que a identidade da pessoa pode ser preservada pela identidade do homem: pessoa e homem estão conectados por meio da noção de corpo. Estas discussões são realizadas a partir sobretudo - mas não exclusivamente - da leitura do capítulo 'Da identidade e diversidade', do Ensaio de Locke, da seção 'Sobre a explicação do Senhor Locke de nossa identidade pessoal', dos Poderes intelectuais de Reid, e de comentários presentes na literatura secundária acerca da teoria lockiana da identidade pessoal.

Antes de me deter sobre o desenvolvimento de meus argumentos, gostaria de observar que, neste artigo, faço um uso intercambiável dos termos pessoa, identidade pessoal e eu (self). Para Locke e Reid, pessoa, identidade pessoal e eu designam aquilo 
que cada ser humano é ou acredita ser, aquilo que tem desejos, sonhos, expectativas, um certo padrão de comportamento e perdura ao longo do tempo. Pessoa, identidade pessoal e eu designam aquilo que continua a existir, apesar de estar em constante transformação, sem deixar, no entanto, de ser o que é ou acredita ser.

\section{A teoria lockiana da identidade pessoal}

De modo didático, o capítulo 'Da identidade e diversidade' pode ser dividido em duas partes. Na primeira parte do texto, Locke discute o principium individuationis dos seres existentes, o fundamento real da individualidade de cada ser. Segundo Locke, o princípio que individua o ser é a existência em si, na medida em que ela "determina um ser de qualquer tipo a um tempo e espaço específicos, intransmissíveis a dois seres do mesmo tipo" (1999, p.435). Se um objeto qualquer é passível de ser distinguido em relação a outros objetos semelhantes, isso só é possível na medida em que sua própria existência o torna um objeto particular, realmente distinto dos demais.

Da consideração do principium individuationis, Locke passa então a explicar de que modo este princípio faz com que a mente humana conceba os seres como os mesmos seres. A questão diz respeito à origem da ideia da identidade de um ser. A transição repentina da explicação do que é o principium individuationis à explicação da ideia de identidade torna alguns pontos do texto lockiano de difícil interpretação. Segundo Joanna Forstrom (2010), a melhor maneira de se compreender essa transição é aceitar que Locke está lidando com uma noção ontológica e uma noção epistêmica (2010, p.19). Sigo a sugestão de Forstrom - a distinção entre uma noção ontológica e uma noção epistêmica - em minha interpretação. Por um lado, quando o filósofo se refere ao principium individuationis, ele tem em vista uma noção ontológica, ou seja, um princípio que individua o ser na realidade, o que torna o objeto real um ser individual em relação a outros objetos. Por outro, ao se referir à ideia de identidade, Locke tem em vista uma noção epistêmica, isto é, a ideia que a mente forma para si de um objeto como o mesmo objeto. Para Locke, de acordo com a distinção entre uma noção ontológica e uma noção epistêmica, o modo como o principium individuationis determina a identidade de um ser na realidade (noção ontológica) e, por consequência, na mente (noção epistêmica), distingue-se de acordo com o tipo de substância: se ela é uma substância simples ${ }^{4}$, uma substância composta ${ }^{5}$, uma criatura viva como um vegetal ${ }^{6}$, um animal irracional ${ }^{7}$ ou um homem ${ }^{8}$.

Assim o filósofo adentra, na segunda parte do texto, a discussão do problema da identidade pessoal. Locke nota que é preciso distinguir entre as noções de homem e pessoa. Homem designa não um ser pensante, mas um animal com uma forma corporal específica, a forma humana (1999, pp.439-40). Pessoa, por sua vez, significa "[...] um ser inteligente pensante, que possui raciocínio e reflexão, e que se pode 
pensar a si próprio como o mesmo ser pensante em diferentes tempos e espaços" (1999, pp.442-43). Na quarta seção deste artigo, volto à discussão desta distinção. Por ora, gostaria de chamar atenção, nesta última passagem, à referência do filósofo à faculdade mental que permite com que a pessoa pense a si própria como a mesma pessoa, faculdade denominada por Locke de consciência. É justamente nessa volta sobre si permitida pela consciência, segundo o filósofo, que a pessoa descobre sua identidade:

Uma vez que a consciência acompanha sempre o pensamento e é o que faz com que cada um seja ele próprio e, desse modo, se distinga de todas as outras coisas pensantes, é somente nisto que consiste a identidade pessoal, ou seja, a singularidade de um ser racional (Locke, 1999, p.443).

A pessoa descobre a própria existência contínua, como mesma pessoa, pela faculdade da consciência. O filósofo continua:

Até onde esta consciência retroceder, em direção a uma ação ou pensamento passado, aí chega a identidade dessa pessoa; é o mesmo eu agora e no passado, e é por esse mesmo eu em conjunto com o eu do presente, que agora reflete acerca do passado, que essa ação foi realizada (Locke, 1999, p.443).

A preservação da identidade pessoal para Locke independe de uma substância, seja ela material ou imaterial, simples ou composta9 ${ }^{9}$ :

Visto que é pela consciência que possui dos pensamentos e ações do presente que o eu é agora para si próprio, e assim será o mesmo eu na medida em que a mesma consciência se possa alargar a ações passadas ou futuras; e não seria duas pessoas, pela distância temporal ou pela alteração da substância, tal como um homem não seria dois homens por vestir hoje roupa diferente da de ontem, independentemente de ter dormido muito ou pouco tempo (Locke, 1999, pp.444-45).

Locke abandona a questão de saber da relação entre a identidade e a substância: "a questão é saber o que constitui a mesma pessoa e não se é a mesma substância correspondente que raciocina sempre na mesma pessoa, o que, neste caso, não interessa de forma alguma" (1999, p.444).

A pergunta que norteia a discussão da próxima seção pode ser expressa nos seguintes termos: como entender estas afirmações de Locke acerca da relação entre consciência e identidade pessoal? Como argumentarei, o modo de responder a esta questão permite mostrar que objeção reidiana parte de uma interpretação equivocada da teoria lockiana da identidade pessoal. 


\section{A continuidade ontológica da consciência}

Reid interpreta o texto lockiano como se o filósofo afirmasse que a identidade da pessoa fosse constituída somente por aquilo que as operações da consciência oferecem à pessoa. Isto é, a identidade pessoal seria um produto de operações desta faculdade da mente. Por trás da compreensão de Reid, está o pressuposto de que que Locke defendeu uma teoria da identidade pessoal baseada sobre a continuidade psicológica da consciência: a pessoa é aquilo de que ela é capaz de ter consciência. Johan Gustafsson (2010) sumariza esta chave de interpretação de acordo com o seguinte critério - que procuro adaptar para os termos da discussão proposta neste artigo:

Critério baseado sobre a continuidade psicológica da consciência ${ }^{10}$ : uma pessoa $P^{1}$ que existe em $T^{1}$ é idêntica à pessoa $P^{2}$ que existe tempos depois em $T^{2}$ se $P^{2}$ está consciente em $T^{2}$ de pensamentos e ações de $P^{1}$ em $T^{1}$ (2010, p.113).

De acordo com esta compreensão e o exemplo do oficial corajoso, a criança açoitada que viveu, por exemplo, em 1725, é o oficial que tomou o estandarte do inimigo em 1740, pois o oficial está consciente de ter sido açoitado 15 anos antes. O general que vive em 1785 é o oficial que tomou o estandarte em 1740 porque está consciente deste ato heroico realizado 45 anos antes. $O$ general, contudo, não é a criança açoitada 60 anos antes, uma vez que não está consciente deste episódio de sua vida. A consciência, por sua descontinuidade, não é capaz de unir a criança e o general, muito embora o general seja o oficial e o oficial seja a criança, de modo que "o general é e ao mesmo tempo não é a mesma pessoa que foi açoitada na escola" (2002, p.276). Além do próprio Reid, intérpretes como Anthony Flew (1951) ${ }^{11}$ e Henry Allison ${ }^{12}$ (1966), por exemplo, seguem esta chave de interpretação: a identidade pessoal, para Locke, dependeria da continuidade psicológica da consciência, sendo ela um produto das operações desta faculdade.

Outra linha de interpretação da teoria lockiana é aquela que diz que a chave para se entender o texto de Locke não é a noção de consciência, mas a noção de apropriação. Dentre estes intérpretes, cito três exemplos. Kenneth Winkler (1991) propõe que Locke não estaria interessado por ações e pensamentos que a consciência não pudesse retomar. A seu ver, o eu lockiano seria um eu constituído somente por aqueles pensamentos e ações de que a pessoa pudesse se apropriar ${ }^{13}$. Giddeon Yaffe (2007) segue os passos de Winkler: o general se apropriaria indiretamente dos pensamentos e ações do garoto por meio do oficial corajoso que se apropria diretamente dos pensamentos e ações do garoto ${ }^{14}$. Na mesma via de interpretação, Shelley Weinberg (2011) propõe a noção de um eu intermediário: a pessoa que tomou o estandarte (intermediária) se lembra da pessoa que foi açoitada, e isso seria suficiente para que 
a pessoa açoitada fosse a mesma pessoa que se tornou general, desde que esta última tenha consciência de ter sido a pessoa que tomou o estandarte ${ }^{15}$.

A defesa por meio da noção de apropriação, a meu ver, apresenta dificuldades na medida em que parte do pressuposto, assim como a objeção apresentada por Reid, de que a teoria da identidade pessoal de Locke é fundada sobre a continuidade psicológica da consciência, ou seja, de que as operações desta faculdade produziriam a identidade pessoal. Neste sentido, autores que a assumem pretendem responder a objeção nos próprios termos colocados por Reid, como se de fato houvesse um problema com os limites da faculdade da consciência - sua incapacidade de retomar todos os fatos passados ${ }^{16}$. A alternativa que apresento adiante, diferentemente desta solução a partir da apropriação, recusa-se a discutir a objeção nos termos colocados por Reid, pois afirma que esta objeção parte de um pressuposto equivocado: a teoria da identidade pessoal de Locke não depende da continuidade psicológica da consciência. $O$ fato de que esta faculdade não é capaz de retomar todos os eventos passados da vida de uma pessoa não é um problema porque a identidade pessoal é baseada na continuidade da existência da consciência.

Entendo que, para Locke, a identidade pessoal depende de uma continuidade ontológica: a pessoa é a mesma pessoa enquanto existe uma mesma consciência ao longo do tempo. Sublinho uma passagem do texto lockiano como evidência para essa interpretação: "visto que é pela consciência que possui dos pensamentos e ações do presente que o eu é agora para si próprio, e assim será o mesmo eu na medida em que a mesma consciência [itálico meu] se possa alargar a ações passadas ou futuras; [... ]" (1999, p.444). O que importa, na explicação do eu é a continuidade ontológica da consciência. A mesma consciência faz a identidade pessoal, ainda que a pessoa não seja capaz de estar consciente de episódios passados de sua vida. Deste modo, sugiro que o critério adequado para a teoria da identidade pessoal de Locke poderia ser expresso da seguinte forma:

Critério baseado sobre a continuidade ontológica da consciência: uma pessoa $P^{1}$ que existe em $T^{1}$ é idêntica à pessoa $P^{2}$ que existe tempos depois em $T^{1}$ se a consciência de $P^{2}$ em $T^{1}$ é a mesma consciência de $P^{1}$ em $T^{1}$ (2010, p.113).

Se estou certo em minha interpretação, Locke apoia sua teoria da identidade pessoal sobre um pressuposto ontológico: a existência contínua da consciência. A pessoa é a mesma pessoa desde que a consciência tenha existido continuamente.

Pensando a partir da distinção concebida por Forstrom, apresentada na segunda seção, sobre a existência tanto de uma noção ontológica quanto de uma noção epistêmica no texto de 'Da identidade e diversidade', entendo que, para Locke, a consciência é o principium individuationis (noção ontológica), ou seja, o princípio que 
individua a pessoa na realidade, o que torna o eu um ser individual em relação a outras existências. A ideia que o indivíduo tem de sua própria pessoa, a ideia que a pessoa forma de si mesma e para si mesma como a mesma pessoa (noção epistêmica), é determinada pela consciência (noção ontológica), o principium individuationis. Locke parece apontar neste sentido quando diz, por exemplo: "a consciência acompanha sempre o pensamento e é o que faz com que cada um seja ele próprio e, desse modo, se distinga de todas as outras coisas pensantes" (1999, p.443). A existência da consciência, portanto, é o que torna uma pessoa uma existência contínua distinta de outras existências. A consciência é, portanto, o principium individuationis da pessoa.

$\mathrm{Na}$ interpretação de Reid, a teoria lockiana da identidade pessoal pressupõe a continuidade psicológica da consciência. A identidade pessoal é um produto das operações da consciência. A meu ver, esta compreensão está equivocada, se as considerações apresentadas acima estiverem corretas. Sua objeção não atinge a teoria de Locke na medida em que ela não se apoia sobre a continuidade psicológica da consciência. Muito embora uma pessoa não seja capaz de ter consciência de todos os episódios passados de sua vida, a existência de uma mesma consciência preserva a identidade dessa pessoa. A objeção de Reid não atinge a teoria lockiana porque o garoto açoitado, o oficial corajoso e o general são a mesma pessoa, mesmo que este último não esteja consciente daquele castigo de infância, pois o garoto, o oficial e o general são dotados da mesma consciência. A consciência é o princípio que os torna a mesma pessoa, uma pessoa distinta de todas as outras.

Considero relevante a consideração de Margaret Atherton (1983) sobre o quão implausível é supor que Locke teria baseado sua teoria da identidade pessoal sobre operações de uma faculdade mental que tem limites no tocante à sua capacidade de informar sobre acontecimentos passados:

[... ] Não há nenhuma razão para acreditar que Locke não estava ciente destes pontos que causam dificuldades para esta teoria ou que ele teria considerado esta teoria, que ignorou estas dificuldades, aceitável. Locke certamente não pensou que nós temos uma recordação total [total recall]. Portanto, não há razão para acreditar que Locke pensaria que uma ideia de identidade pessoal baseada sobre a memória não deixaria lacunas [...] (Atherton, 1983, p.276, tradução minha).

Locke sabe que os seres humanos são incapazes de estar completamente conscientes de episódios passados de suas vidas. Grande parte da humanidade não é capaz desta recordação total do passado. Não há motivos para supor que ele construiria sua teoria sobre este pressuposto da continuidade psicológica da consciência. Ademais, reconheço o débito que minha interpretação da teoria lockiana da identidade pessoal e, consequentemente, a tentativa de defendê-la da objeção reidiana, tem com 
algumas sugestões feitas por Atherton. A intérprete nota, com efeito: "dizer que o eu estende-se seria dizer que o mesmo eu é encontrado onde quer que pensamentos, percepções ou o que quer que seja, sejam devidos à mesma consciência" (1983, p.278, tradução e itálico meus). A intérprete também parece sugerir que a preservação da identidade pessoal em Locke supõe um pressuposto ontológico. Isto fica mais claro quando Atherton apresenta uma analogia - entre os papéis da consciência e de uma única vida para a preservação das identidades da pessoa e dos seres vivos sugerindo, por outras palavras, que a consciência seria o principium individuationis da identidade pessoal:

Parece razoável pressupor que, em seu critério para a identidade de pessoas, Locke está procurando por algo análogo ao seu critério de uma única vida para os organismos. [...] Ele procurará algum modo individuante de ser, cuja presença desde o início da pessoa diferenciará aquela pessoa de todas as outras e a existência continuada da qual preservará a existência continuada da pessoa distintiva (Atherton, 1983, pp.282-83, tradução minha).

A consciência está para o eu assim como uma única vida está para os seres vivos (plantas, animais e homens). Isto é, assim como a vida individua as plantas, animais e homens, a consciência individua o eu. Sugestões como estas me impeliram a refletir sobre a possibilidade de Locke estar pensando na consciência à maneira de principium individuationis da identidade pessoal. A hipótese de um pressuposto ontológico na teoria da identidade pessoal de Locke surgiu, portanto, da reflexão a partir de leitura de passagens do trabalho de Atherton.

Mais recentemente, Weinberg (2012) parece ter abandonado a explicação da identidade pessoal pela apropriação ${ }^{17}$ para seguir uma interpretação semelhante a que proponho. A intérprete defende a hipótese de que existe um fato metafísico na teoria lockiana, um eu contínuo revelado em toda operação de estar consciente. Sua interpretação é baseada sobre a distinção entre duas noções de consciência:

No capítulo dedicado à identidade pessoal, Locke parece ver a consciência como 1) um estado mental inseparável de um ato de percepção por meio do qual estamos cientes de nós mesmos como percipientes, e como 2) o eu contínuo de que estamos conscientes nesses estados de consciência (Weinberg, 2012, p. 390, tradução minha).

A primeira noção refere-se ao aspecto psicológico da consciência; a segunda, a um fato metafísico, um eu contínuo ou consciência existente para além do âmbito psicológico das operações mentais:

O segundo sentido de consciência, necessário para responder às objeções, é o fato objetivo de uma consciência contínua. [... O O eu contínuo de que 
estou ciente [aware] ao estar consciente de pensamentos e ações passadas e presentes parece ter também uma existência temporal continuada através de qualquer lacuna nos sucessivos estados de consciência [awareness] que tenho de mim mesmo (Weinberg, 2012, p.390-1, tradução minha).

Por trás da continuidade e das lacunas psicológicas da consciência, há um eu contínuo, um fato metafísico.

Em termos gerais, minha proposta de interpretação é semelhante à de Weinberg: há um pressuposto ontológico — fato metafísico, como quer a autora — na teoria lockiana da identidade pessoal. O modo como encontro minha solução, contudo, é distinto da via proposta pela autora. Enquanto apelo à noção de principium individuationis, Weinberg recorre a uma distinção entre duas noções de consciência. Tenho a dizer, em defesa de minha interpretação, que ela se vale de noções encontradas no próprio texto de Locke para explicar sua teoria da identidade pessoal. Antes de distinguir entre duas noções de consciência que, ainda que sejam coerentes com o que é apresentado pelo filósofo em seu texto, estão implícitas no escrito, escolho pensar a consciência como um principium individuationis que individua a pessoa na realidade, traçando um paralelo entre a discussão empreendida por Locke nos primeiros parágrafos de 'Da identidade e diversidade' com a subsequente discussão da identidade pessoal naquele mesmo capítulo. Nesta interpretação, opto por recorrer a conceitos explícitos no texto lockiano para compreender em que medida a objeção colocada por Reid parte de um entendimento equivocado da mesma.

Antes de concluir esta seção, noto que nos Poderes intelectuais, além da objeção discutida acima sobre o problema da continuidade psicológica da consciência (2002, pp.275-76), Reid apresenta quatro observações mais pontuais sobre a teoria lockiana. Comentarei mais detidamente a primeira e a segunda destas observações que, a meu ver, parecem mais contundentes para a teoria de Locke ${ }^{18}$.

Na primeira observação, Reid sugere que Locke teria confundido as operações da consciência com as operações de outra faculdade, a memória (2002, p.277). Esta observação merece um esclarecimento. A psicologia das faculdades da mente de Reid é sistematicamente desenvolvida, de modo que as faculdades da mente são, tanto quanto possível, rigorosamente distinguidas ao longo de suas obras. A memória, e somente a memória, é capaz de atestar a existência de acontecimentos do passado ${ }^{19}$. A consciência, por sua vez, é a faculdade por meio do qual se conhece o que se passa no interior da mente no momento presente - as paixões e sentimentos, por exemplo ${ }^{20}$. Em uma perspectiva reidiana, a faculdade da consciência jamais poderia atestar a existência de eventos do passado, uma operação que é própria somente da memória. Este é o ponto de apoio desta primeira observação. Claramente, ao menos no texto 'Da identidade e diversidade', Locke não faz a distinção sistemática entre uma e outra faculdade, entendendo a consciência como uma operação capaz de ofe- 
recer conhecimento sobre acontecimentos passados. Em resposta a esta observação, noto que, embora Reid atribua este equívoco a Locke, todo o seu argumento sobre o problema da continuidade psicológica da consciência é construído pressupondo que a consciência seria capaz de atestar fatos passados. Isto é, Reid aceita a identificação entre as duas faculdades realizada por Locke para, na sequência, questioná-la a partir do problema da incapacidade da pessoa de estar consciente de todos os acontecimentos de seu passado. É notável que mesmo os intérpretes do texto lockiano não consideram esta distinção. Gustafsson, por exemplo, apresenta um critério de memória da identidade pessoal - que adapto para critério baseado na continuidade psicológica da consciência, procurando manter-me fiel à letra do texto de Locke. Para a interpretação que proponho, importa notar apenas que é a continuidade ontológica de uma faculdade da mente que garante a identidade pessoal, ainda que, em uma perspectiva reidiana, seja problemático atribuir à consciência a capacidade de retomar acontecimentos do passado.

A segunda observação de Reid afirma que Locke teria confundido a identidade pessoal com a evidência que o ser humano tem da identidade de sua pessoa (2002, pp.277-78). Isto é, Locke teria confundido a faculdade por meio da qual a pessoa sabe do seu eu com a própria identidade pessoal. Noto que, assim como a objeção sobre a continuidade psicológica da consciência, este comentário de Reid é baseado sobre o pressuposto de que são as operações das faculdades da mente que produzem a identidade pessoal. O eu seria um produto de operações da consciência, uma faculdade que, na verdade, apenas revelaria a existência do eu - em uma perspectiva reidiana ${ }^{21}$. Como argumentei nos parágrafos acima, a consciência não produz a identidade pessoal na teoria lockiana. O eu não é resultado de operações desta faculdade. É a existência de uma mesma consciência, no passado e presente, que garante a mesma pessoa ao longo do tempo. Portanto, não haveria, tal como entendo, uma confusão, da parte de Locke, entre a evidência da existência de um eu e o próprio eu.

\section{A conexão entre homem e pessoa}

Na seção acima, argumentei que a objeção de Reid parte de um pressuposto equivocado no tocante à compreensão da teoria da identidade pessoal de Locke, a saber, que a identidade da pessoa depende da continuidade psicológica da consciência. Nesta seção, apresento uma tentativa de resposta assumindo os termos colocados por Reid em sua objeção, isto é, a partir da observação dos limites da faculdade da consciência no tocante a oferecer conhecimento sobre o passado. Esta via de defesa de sua teoria é baseada sobre a própria sugestão de Locke acerca de como a identidade pessoal é preservada em casos de amnésia. O filósofo diz, com efeito: "suponhamos que eu perco completamente a memória em relação a certas partes da minha vida. [...] 
Mas eu não sou a mesma pessoa que praticou essas ações, que teve esses pensamentos, dos quais um dia tive consciência, embora neste momento os tenha esquecido" (1999, p.453)? Locke responde diretamente à objeção - mais tarde colocada por Reid - recorrendo à noção de homem. A identidade do homem seria capaz de preservar a identidade da pessoa: "respondo que aqui temos de ter em conta a que é que a palavra eu é aplicada, o que, neste caso, é apenas ao homem e que, presumindo-se que o mesmo homem seja a mesma pessoa, também aqui eu facilmente se supõe que representa a mesma pessoa" (1999, p.453). É possível atribuir a uma pessoa pensamentos e ações de que ela não tem consciência na medida em que o homem que as realizou é o mesmo homem.

Tanto quanto sei, nenhuma atenção foi dada pelos intérpretes a esta sugestão de Locke. A dificuldade desta resposta de Locke refere-se à distinção realizada por ele próprio entre as noções de homem e pessoa. Ele diz, sobre a primeira destas noções:

A ideia nas nossas mentes, da qual o som homem que sai das nossas bocas é o sinal, não é mais do que a de um animal com uma certa forma. Uma vez que julgo poder estar confiante de quem quer que visse uma criatura com a mesma forma ou estrutura que a sua, embora não tivesse mais raciocínio em toda a sua vida que um gato ou um papagaio, continuaria a chamá-la homem, [...] (Locke, 1999, p.439).

Enquanto homem significa um animal com uma forma corporal específica, pessoa significa um ser inteligente pensante, capaz de raciocínio e reflexão. Por um lado, Locke parece entender que o homem é definido em termos puramente corporais, por outro, parece entender que a pessoa é definida em termos puramente mentais, existindo assim uma distinção radical entre ambos. Flew e Bennett (1999), por exemplo, acreditam que esta é a compreensão de Locke. Contra estas interpretações, tenho a dizer que, embora as noções de homem e pessoa tenham sido distinguidas por Locke, acredito que há uma maneira de conectá-las de modo a tornar coerente a explicação lockiana de que, em casos de amnésia, pode-se recorrer à noção de homem. Por meio da noção de corpo, Locke pode aproximar, diferentemente do que pensa Flew ${ }^{22}$, ambas as noções; do mesmo modo, esta conexão permite definir a noção de pessoa tanto em termos mentais quanto em termos corporais, contrariando o que Bennett ${ }^{23}$ pensa. Uma pessoa é um corpo e, como tal, um homem.

Para Locke, a noção de pessoa envolve, além de uma dimensão mental, uma dimensão corporal. Explico mais claramente. O eu lockiano integra tanto uma mente — pensamentos, sentimentos, e responsabilidade por ações - quanto um corpo, pois o eu é constituído por todas aquelas partes acompanhadas pela consciência: "aquilo com que a consciência desta coisa racional presente se pode associar forma a mesma pessoa e é um eu em si, sem nada mais" (1999, p.452). Por isso, os dedos que formam a mão, os membros que formam o corpo, o próprio corpo, constituem o eu: "qualquer 
parte dos nossos corpos, unidos de forma vital com o que é consciente em nós, faz parte de nós próprios" (1999, p.458). Se, porventura, um dedo é separado da mão, modificando assim o corpo humano, a identidade do eu não é de modo algum afetada, do mesmo modo que o esquecimento de um episódio do passado não ameaça a preservação da identidade pessoal. A mesma pessoa permanece, ainda que sem um dedo. A noção de pessoa possui uma dimensão corporal; a noção de homem também envolve este aspecto. Pessoa e homem estão conectados por meio do corpo.

Além de Locke, David Hume (1711-1776) também integra o corpo ao eu em sua teoria da identidade pessoal apresentada nos Livros I e II do Tratado da natureza humana (1739-40) ${ }^{24}$. Para Hume, o eu deve ser entendido não apenas como uma mente mas também como um corpo, como ele o afirma, por exemplo, na seguinte passagem: "embora o orgulho e a humildade tenham como causas naturais e mais imediatas os atributos de nossa mente e corpo, isto é, do eu [... ]" (2001, p.337). A explicação de Hume da integração do corpo considera as operações da paixão na natureza humana, em especial, as paixões do interesse próprio, orgulho e humildade ${ }^{25}$. Locke explica a conexão entre pessoa e corpo pela integração do corpo ao eu pela consciência.

Portanto, argumento que, por meio da noção de corpo, Locke pode relacionar o eu e o homem de modo a defender-se da objeção reidiana de uma maneira alternativa àquela apresentada na seção anterior. A identidade do homem é preservada tal qual a identidade de outros seres vivos: ela "nada mais [é] do que a comunhão da mesma vida contínua através das partículas contínuas e transitórias de matéria, que numa sucessão estão unidas na vitalidade ao mesmo corpo organizado" (1999, p.438). O mesmo homem é aquele que possui um corpo organizado cujas partes são unidas pela mesma vida e, sua identidade vem em auxílio da identidade pessoal, sendo ela aquilo que une a pessoa do passado (que pensou e realizou as ações passadas) à pessoa do presente. Homem e pessoa, apesar de distintos, conectam-se mediante o corpo integrado ao eu:

Critério baseado sobre a conexão entre homem e pessoa: uma pessoa $P^{1}$ que existe em $T^{1}$ é idêntica à pessoa $P^{2}$ que existe tempos depois em $T^{2}$ se $P^{2}$ é o mesmo homem que $P^{1}$ é em $T^{1}$.

O mesmo homem, enquanto um animal que possui um corpo de determinada forma, conectado aos pensamentos, sentimentos e ações, faz a mesma pessoa, muito embora esta pessoa possa não se recordar de episódios passados de sua vida. O homem que se tornou general é o mesmo homem que foi açoitado na infância e, portanto, ambos são a mesma pessoa, pois compartilham o mesmo corpo. 


\section{Considerações finais}

Procurei neste artigo defender a teoria da identidade pessoal de Locke da objeção de Reid. A teoria lockiana é capaz de explicar de que modo um indivíduo é a mesma pessoa ao longo do tempo ainda que não exista uma continuidade psicológica da consciência. O ser humano não é capaz de retomar, a partir de suas faculdades mentais, todos os episódios passados de sua vida. Em geral, uma pessoa não está consciente de todos os pensamentos e ações de seu passado. Contudo, isto não é um problema da teoria lockiana. Apresentei, na verdade, duas alternativas de resposta à objeção reidiana. Em primeiro lugar, argumentei que a crítica não é efetiva na medida em que parte de uma compreensão equivocada da teoria lockiana da identidade pessoal. A identidade da pessoa é preservada não pela continuidade psicológica da consciência, como Reid acredita, mas por sua continuidade ontológica. A identidade da pessoa é preservada pela existência contínua de uma mesma consciência. Neste sentido, o general, o oficial corajoso e a criança açoitada são a mesma pessoa porque possuem a mesma consciência. Em segundo lugar, procurei argumentar que há uma via alternativa de defesa a partir da observação de que pessoa e homem estão conectados por meio do corpo. Tentei mostrar que Locke concebe que o eu possui tanto uma dimensão mental como uma dimensão corporal. Este aspecto corporal é capaz de unir a pessoa e o homem - definido pelo filósofo em termos puramente corporais. Neste sentido, o general, o oficial corajoso e a criança açoitada são a mesma pessoa porque são o mesmo homem, e a pessoa está conectada ao homem por um corpo.

\section{Referências}

Allison, H. 1966. Locke's Theory of Personal Identity: A Re-Examination. Journal of the History of Ideas. Volume XXVII, número 1, pp.41-58.

Alston, W., Bennett, J. 1988. Locke on People and Substances. The Philosophical Review. Volume XCVII, número 1, pp.25-46.

Atherton, M. 1983. Locke's Theory of Personal Identity. Midwest Studies in Philosophy. Volume VIII, número 1, pp.273-293.

Bennett, J. 1999. Locke's Philosophy of Mind. The Cambridge Companion to Locke. Vere Chappell (editora). Cambridge: Cambridge University Press, pp. 89-114.

Boeker, R. 2016. The Role of Appropriation in Locke's Account of Persons and Personal Identity. Locke Studies. Volume XVI.

Flew, A. 1951. Locke and the Problem of Personal Identity. Philosophy. Volume XXVI, número 96, pp.53-68.

Forstrom, J. 2010. John Locke and Personal Identity: Immortality and Bodily Ressurrection in Seventeenth-Century Philosophy. London e New York: Continuum.

Freitas, V. 2019 David Hume sobre a identidade pessoal nos Livros I e II do Tratado da natureza humana. Unisinos Journal of Philosophy. Volume XX, número 1, pp.46-54. 
Gordon-Roth, J. 2015. Locke on the Ontology of Persons. The Southern Journal of Philosophy. Volume LIII, número 1, pp.97-123.

Gustafsson, J. 2010. Did Locke Defend the Memory Continuity Criterion of Personal Identity? Locke Studies. Volume X, pp.113-129.

Hume, D. 2001. Tratado da Natureza Humana. Deborah Danowski (tradutora). São Paulo: Editora UNESP — Imprensa Oficial do Estado.

Locke, J. 1999. Ensaio sobre o Entendimento Humano. Eduardo Abranches Soveral (tradutor). Lisboa: Fundação Calouste Gulbenkian.

McIntyre, J. 2009. Hume and the Problem of Personal Identity. The Cambridge Companion to Hume: Second Edition. David Norton (editor). Cambridge: Cambridge University Press.

Reid, T. 2002. Essays on the Intellectual Powers of Man. Derek Brookes (editor). Edinburgh: Edinburgh University Press.

Simendic, M. 2015. Locke's Person is a Relation. Locke Studies. Volume 15, pp.79-97.

Uzgalis, W. 1990. Relative Identity and Locke's Principle of Individuation. History of Philosophy Quarterly. Volume VII, número 3, pp.283-297.

Weinberg, S. 2011. Locke on Personal Identity. Philosophy Compass. Volume VI, número 6, pp.398-407.

Weinberg, S. 2012. The Metaphysical Fact of Consciousness in Locke's Theory of the Personal Identity. Journal of the History of Philosophy. Volume L, número 3, pp.387-415.

Winkler, K. 1991. Locke on Personal Identity. Journal of the History of Philosophy. Volume XXIX, número 2, pp.201-226.

Yaffe, G. 2007. Locke on Ideas of Identity and Diversity. The Cambridge Companion to Locke's 'Essay Concerning Human Understanding. Lex Newman (editor). Cambridge: Cambridge University Press, pp.191-230.

\section{Notas}

${ }^{1}$ A primeira edição do Ensaio foi publicada em dezembro de 1689 . O capítulo 'Da identidade e diversidade' foi adicionado por Locke à segunda edição, publicada cinco anos mais tarde. Este acréscimo foi feito por uma sugestão de seu interlocutor e correspondente William Molyneux, que teria aconselhado o filósofo a apresentar suas considerações sobre temas que facilitariam a adoção de sua obra pelos escolásticos da Universidade de Oxford. Os temas eram o principium individuationis e a questão da identidade. Ver Joanna Forstrom (2010, pp.6-7).

${ }^{2}$ Alguns autores que discutiram o problema da identidade pessoal no período: Henry Lee (1644-1713), em Anticeticismo (1702), Anthony Ashley-Cooper, o 3o Conde de Shaftesbury (1671-1713), em Os moralistas (1709) e nas Características (1711), Samuel Clarke (16751729) e Anthony Collins (1676-1729), que mantiveram um debate intenso sobre a questão por correpondência, e David Hume (1711-1776), no Tratado da natureza humana (173940). Ver Jane McIntyre (2009, pp.179-82).

${ }^{3}$ Antes de Reid, a teoria lockiana da identidade pessoal recebeu críticas de filósofos como, por exemplo, George Berkeley (1685-1753), no diálogo Alcifron (1732), Joseph Butler (1692-1752), em um apêndice de Analogia da religião (1736), e G. W. Leibniz (1646-1716), nos seus Novos ensaios sobre o entendimento humano (1765). 
4“É evidente que, quando considerado num qualquer momento da sua existência, nesse momento ele é o mesmo em si próprio [... E E dessa forma tem de continuar a ser enquanto a sua existência perdurar; e durante esse período será o mesmo e não outro" (1999, p.436).

5 "Enquanto eles existirem agrupados, a massa, constituída pelos mesmos átomos, tem de ser a mesma massa ou o mesmo corpo, ainda que as suas partes se misturem de formas diversas" (1999, p.436). Nota-se que a identidade desses tipos de substância é determinada pela quantidade de massa. A massa de três átomos unidos, por exemplo, determina a identidade de uma substância composta desde que nenhum átomo seja subtraído ao adicionado ao conjunto. Neste exemplo, um pequeno decréscimo ou acréscimo no número total de átomos é suficiente para destruir a identidade da substância.

6"Aí que reside a vida singular que, existindo de forma constante a partir desse momento, daí para frente e daí para trás, na mesma continuidade de partes imperceptíveis que se sucedem, unidas ao corpo vivo da planta, tem essa identidade que constitui a mesma planta" (1999, p.437). A identidade de um vegetal depende de uma composição de partes organizadas e unidas por uma mesma vida.

${ }^{7}$ O filósofo, neste ponto, recorre a uma analogia. Um relógio é uma organização de partes tendo em vista um determinado fim (indicar as horas), e "se imaginássemos esta máquina como um corpo contínuo, cujas partes fossem todas reparadas, aumentadas ou diminuídas através de uma constante adição ou separação das partes imperceptíveis, com uma vida comum, teríamos algo muito semelhante ao corpo de um animal" (1999, pp.437-38). A identidade dos animais, portanto, consiste em uma união de partes que compartilham uma mesma vida.

${ }^{8} \mathrm{~A}$ identidade do homem não é "nada mais do que a comunhão da mesma vida contínua através das partículas contínuas e transitórias de matéria, que numa sucessão estão unidas na vitalidade ao mesmo corpo organizado" (1999, p.438).

${ }^{9}$ No capítulo 'Da identidade e diversidade', Locke apresenta três tipos de substâncias: Deus, inteligências finitas e corpos (1999, p.434). Após apresentá-las, ele acrescenta que todas as outras existências são relações ou modos (1999, p.435). Desta observação, surge o debate na literatura secundária sobre saber se Locke entende a pessoa ou o eu como uma substância, uma relação ou um modo. Há, na literatura secundária, uma discussão a esse respeito. Autores como William Alston e John Bennett (1988) defendem que, para Locke, "uma pessoa é uma substância, onde o termo é tomado em seu uso mais amplo; mas é uma substância em uso tão amplo que uma mesma pessoa pode envolver um número de substâncias fundamentais, sendo elas materiais ou imateriais. Portanto, a identidade de uma pessoa não carrega necessariamente consigo a identidade de uma única substância de tipo básico do qual as pessoas são compostas" (1988, p.40, tradução minha). Jessica Gordon-Roth (2015) também afirma o mesmo: pessoas são substâncias porque 1) pessoas são agentes e apenas substâncias são agentes; 2) pessoas têm poderes e apenas substâncias têm poderes (2015, pp.100-102). Afastando-se desta leitura, Marko Simendic (2015) defende que a noção de pessoa deve ser entendida como relação: "pessoa é o que Locke chama de ideia complexa e sua definição compreende [...] dois elementos principais - substância e identidade pessoal. Vejo esta segunda como uma relação entre múltiplas interações diacrônicas da mesma consciência que dá á pessoa sua extensão temporal" (2015, p.80, tradução minha). Por fim, diferentemente das duas interpretações anteriores, William Uzgalis (1990) entende que, para Locke, pessoas são modos: "carvalhos, cavalos e pessoas individuais são modos mistos. Um 
modo misto particular é uma organização funcional de substâncias. Na maior parte dos casos, que inclui coisas e pessoas vivas, o modo persiste ou poderia persistir através das mudanças na substância de que ele depende. Por outro lado, modos que têm substâncias como partes herdam algumas propriedades destas partes. É por causa desta herança de propriedades que Locke pode dizer que uma pessoa é um ser pensante sem ter que dizer que uma pessoa é uma substância" (1990, pp.284-85, tradução minha).

${ }^{10}$ Gustafsson chama-o de critério de memória da identidade pessoal. Para seguir a terminologia que uso ao longo do artigo, chamo-o de critério baseado sobre a continuidade psicológica da consciência.

${ }^{11}$ Para Flew, a teoria da identidade pessoal de Locke é baseada sobre o seguinte princípio: " $X$, no tempo dois, é a mesma pessoa $Y$, no tempo um, se e somente se $X$ e $Y$ são as mesmas pessoas e $X$ pode se lembrar, no tempo dois, o que $Y$ fez ou sentiu no tempo um" (1951, pp.54-55, tradução minha).

${ }^{12}$ Allison mantém esta leitura da teoria lockiana ao concordar que não apenas a objeção de Reid, mas também as críticas de Berkeley, Butler, Leibniz e Flew (todas empreendidas a partir da observação que a descontinuidade psicológica da consciência cria duas pessoas e não uma única e mesma pessoa), são fatais para a teoria de Locke (1966, p.41).

${ }^{13}$ Segundo Winkler: "se eu não consigo me lembrar de certos pensamentos e ações passadas, então eles não são parte de meu eu. [...]. Eu não me preocupo com eles. Não me apropriei deles. Fosse o eu de alguma maneira constituído independentemente de minha autoconsciência, estes fatos não seriam muito interessantes. Mas porque o eu é constituído pelo que eu assumo estar nele incluído, as ações e pensamentos de que eu não consigo me lembrar não são de modo algum parte de mim. A objeção da amnésia simplesmente desaparece" (1991, p.205, tradução minha).

${ }^{14}$ Yaffe escreve: "para que você possa se apropriar de um ato, você deve fazê-lo ou direta ou indiretamente. Para se apropriar diretamente de um ato, você deve estar consciente de tê-lo realizado; para se apropriar indiretamente de um ato, você deve se apropriar diretamente de um ato de alguma pessoa que se apropria do ato. Portanto, o general se apropriou do ato do garoto, pois ele se apropriou dos atos do soldado que se se apropriou dos atos do garoto ao estar consciente de que ele os realizou" (2007, p.221, tradução minha).

${ }^{15}$ Segundo Weinberg: "podemos estabelecer a identidade com um eu esquecido mediante um eu intermediário (um antepassado) do qual nos lembramos. Logo, o oficial corajoso, que se lembra do açoitamento quando criança e que é lembrado pelo general, serve como uma ligação antepassada entre o general e a criança (2011, p.401, tradução minha). Não é preciso que uma pessoa se lembre de cada uma de suas ações passadas para identificar a pessoa do passado com a pessoa do presente. A identidade pessoal, no exemplo dado por Reid, pode ser preservada ainda que o general não tenha lembranças de ter sido açoitado quando criança.

${ }^{16}$ Sugiro a leitura do artigo de Ruth Boeker, O papel da apropriação na explicação de Locke das pessoas e da identidade pessoal (2016), no qual a autora não apenas mostra as dificuldades de se supor que Locke apresentaria uma teoria do eu a partir da noção de apropriação como apresenta uma nova maneira de se entender a noção referida.

${ }^{17}$ Ver nota 15.

${ }^{18}$ Reid diz na terceira observação que em Locke a identidade da pessoa consistiria em algo - uma faculdade da mente - que está em constante movimento e transformação (2002, p.278). Como a consciência — por sua própria natureza — está em constante movimento, ou 
seja, é uma faculdade que não está sempre a operar, o eu deixaria consequentemente de existir quando suas operações cessassem. Se estou certo em minha interpretação, a identidade pessoal não é produto de operações de faculdades mentais. Ser a mesma pessoa ao longo do tempo não dependeria, assim sendo, de uma faculdade que operasse continuamente ao longo do tempo, mas sim da continuidade ontológica desta faculdade. Na quarta observação, por sua vez, Reid sugere que algumas passagens do texto de Locke seriam ininteligíveis (2002, pp.278-79). Segundo Reid, a operação da consciência em $T^{1}$ é distinta da operação da consciência em $T^{2}$ - sendo as duas operações semelhantes apenas no que diz respeito à sua espécie -, de modo que a pessoa em $T^{1}$ seria distinta da pessoa em $T^{2}$. Assim como na terceira observação, Reid entende que Locke está atribuindo a identidade pessoal a operações da consciência. Como argumentei, esta é uma interpretação equivocada. Ainda que a operação em $T^{1}$ seja uma operação distinta em $T^{2}$, a consciência em ambos os momentos é a mesma consciência - ontologicamente. Portanto, a pessoa é a mesma pessoa, ainda que as operações sejam distintas.

${ }^{19}$ Reid diz: "é pela memória que temos o conhecimento imediato de coisas passadas. Os sentidos nos dão informação de coisas somente enquanto elas existem no momento presente. Esta informação, se não for preservada pela memória, desapareceria instantaneamente e nos deixaria ignorantes como se nunca tivessem acontecido" (2002, p.254).

${ }^{20}$ Reid diz: "consciência é uma operação do entendimento de seu próprio tipo [of its own kind] e não pode ser logicamente definida. Seus objetos são nossas dores, prazeres, esperanças, medos, desejos, dúvidas e nossos pensamentos presentes de todos os tipos. Em uma palavra, todas as paixões e todas as ações e operações de nossas mentes enquanto elas estão presentes. Podemos nos lembrar delas quando elas são passado, contudo, estamos conscientes delas apenas enquanto elas são presentes (2002, p.471).

${ }^{21}$ Para Reid, as faculdades da mente apenas revelam a existência de um eu: "minha identidade pessoal, portanto, implica a existência continuada daquela coisa indivisível que chamo si mesmo [myself]. O que quer que seja este eu, é algo que pensa, delibera, resolve, age e sofre. Eu não sou pensamento, eu não sou ação, eu não sou um sentimento: eu sou algo que pensa e age e sofre" (2002, p.264).

${ }^{22}$ Flew apresenta cinco motivos que, a seu ver, teriam levado Locke à insatisfação com sua teoria da identidade pessoal. Um dentre estes motivos seria justamente uma consequência do afastamento entre as noções de homem e pessoa: "esta definição [de pessoa] perde o significado e o uso ordinários do termo pessoa. Aprendemos a palavra pessoa sendo apresentados a pessoas, encontrando com elas e apertando suas mãos. Elas podem ser inteligentes ou não, introspectivas ou extrovertidas, pretas, brancas, vermelhas ou marrons, mas o que elas não podem ser é desencorpadas ou terem a forma de elefantes (1951, p.59, tradução minha).

${ }^{23}$ Bennett acredita que o eu lockiano é definido exclusivamente em termos mentais, de modo que o eu - mente - e o homem - corpo - não poderiam significar o mesmo ser: a investigação lockiana do eu "[...] é conduzida inteiramente em termos mentalísticos. Para Locke, um homem não é o mesmo que uma pessoa. O homem que agora passa pela minha porta é o homem com quem falei ontem ao meio-dia? Isto depende - e depende apenas - se há o tipo certo de continuidade animal conectando o homem de ontem ao de hoje. Contudo, de acordo com Locke, se a pessoa que agora passa por minha porta é a mesma pessoa com quem falei ontem ao meio-dia depende de uma ligação mental que não tem nenhuma ligação com a continuidade animal. Mesmo se fosse apenas um homem, poderia ser duas pessoas, e 
também não seria absolutamente impossível que fossem homens diferentes e a mesma pessoa (1999, p.104, tradução minha).

${ }^{24}$ Sobre este ponto, ver artigo de minha autoria intitulado David Hume sobre a identidade pessoal nos Livros I e II do Tratado da natureza humana (2019).

${ }^{25} \mathrm{~A}$ pessoa pensa em um certo corpo humano como sendo o seu próprio corpo, e tem interesse por tudo o que lhe aconteceu ou que possa vir a lhe acontecer — sua saúde, seu vigor, sua beleza. Ademais, o indivíduo concebe-se como corpo, assim como concebe-se como uma mente, na medida em que orgulho e humildade tornam-no intrinsecamente ligado a este corpo. A beleza e o vigor corporal, por exemplo, podem ser causas de orgulho para uma pessoa, assim como a fealdade e a debilidade do corpo podem produzir a paixão contrária. O corpo é causa de uma destas duas paixões indiretas, e nestes casos, ele é concebido pelo indivíduo como um elemento intimamente conectado ao eu. No texto humiano encontramos sugestões dessa relação: "quer consideremos o corpo como uma parte de nós mesmos, quer concordemos com aqueles filósofos que o veem como algo externo, devemos admitir que ele está conectado conosco de maneira estreita o bastante para formar uma daquelas duas relações que afirmei serem necessárias para causar orgulho e humildade" (2001, p.332).

\section{Agradecimentos}

O presente trabalho foi realizado com apoio da Coordenação de Aperfeiçoamento de Pessoal de Nível Superior - Brasil (CAPES). Agradeço aos pareceristas da Principia: an International Journal of Epistemology pelas objeções e sugestões que motivaram algumas discussões neste artigo. Seus comentários impeliram-me a aprofundar a discussão com a literatura secundária e a apresentar algumas considerações às observações de Reid sobre a teoria lockiana da identidade pessoal que, originalmente, não estavam presentes no artigo. Agradeço também a Carlota Salgadinho Ferreira pelas valiosas observações e sugestões feitas à primeira versão redigida deste trabalho. 